\title{
Deep brain stimulation outcomes in patients implanted under general anesthesia with frame-based stereotaxy and intraoperative MRI
}

\author{
Caio M. Matias, MD, PhD, ${ }^{2}$ Leonardo A. Frizon, MD, ${ }^{1}$ Sean J. Nagel, MD, ${ }^{1}$ Darlene A. Lobel, MD, ${ }^{1}$ \\ and André G. Machado, MD, PhD'
}

${ }^{1}$ Center for Neurological Restoration, Cleveland Clinic Neurological Institute, Cleveland, Ohio; and 2Ribeirão Preto Medical School, University of São Paulo, Ribeirão Preto, São Paulo, Brazil

\begin{abstract}
OBJECTIVE The authors' aim in this study was to evaluate placement accuracy and clinical outcomes in patients who underwent implantation of deep brain stimulation devices with the aid of frame-based stereotaxy and intraoperative MRI after induction of general anesthesia.

METHODS Thirty-three patients with movement disorders (27 with Parkinson's disease) underwent implantation of unilateral or bilateral deep brain stimulation systems (64 leads total). All patients underwent the implantation procedure with standard frame-based techniques under general anesthesia and without microelectrode recording. MR images were acquired immediately after the procedure and fused to the preoperative plan to verify accuracy. To evaluate clinical outcome, different scales were used to assess quality of life (EQ-5D), activities of daily living (Unified Parkinson's Disease Rating Scale [UPDRS] part II), and motor function (UPDRS part III during off- and on-medication and off- and on-stimulation states). Accuracy was assessed by comparing the coordinates ( $x, y$, and $z$ ) from the preoperative plan and coordinates from the tip of the lead on intraoperative MRI and postoperative CT scans.
\end{abstract}

RESULTS The EQ-5D score improved or remained stable in $71 \%$ of the patients. When in the off-medication/onstimulation state, all patients reported significant improvement in UPDRS III score at the last follow-up $(p<0.001)$, with a reduction of 25.2 points (46.3\%) (SD 14.7 points and $23.5 \%$, respectively). There was improvement or stability in the UPDRS II scores for $68 \%$ of the Parkinson's patients. For 2 patients, the stereotactic error was deemed significant based on intraoperative MRI findings. In these patients, the lead was removed and replaced after correcting for the error during the same procedure. Postoperative lead revision was not necessary in any of the patients. Based on findings from the last intraoperative MRI study, the mean difference between the tip of the electrode and the planned target was 0.82 $\mathrm{mm}$ (SD $0.5 \mathrm{~mm}, p=0.006$ ) for the $x$-axis, $0.67 \mathrm{~mm}$ (SD $0.5 \mathrm{~mm}, p<0.001$ ) for the $y$-axis, and $0.78 \mathrm{~mm}$ (SD $0.7 \mathrm{~mm}, \mathrm{p}=$ 0.008 ) for the $z$-axis. On average, the euclidian distance was $1.52 \mathrm{~mm}$ (SD $0.6 \mathrm{~mm})$. In patients who underwent bilateral implantation, accuracy was further evaluated comparing the first implanted side and the second implanted side. There was a significant mediolateral ( $x$-axis) difference $(p=0.02)$ in lead accuracy between the first (mean $1.02 \mathrm{~mm}, \mathrm{SD} 0.57$ $\mathrm{mm}$ ) and the second (mean $0.66 \mathrm{~mm}, \mathrm{SD} 0.50 \mathrm{~mm}$ ) sides. However, no significant difference was found for the $y$ - and $z$-axes $(p=0.10$ and $p=0.89$, respectively).

CONCLUSIONS Frame-based DBS implantation under general anesthesia with intraoperative MRI verification of lead location is safe, accurate, precise, and effective compared with standard implantation performed using awake intraoperative physiology. More clinical trials are necessary to directly compare outcomes of each technique.

https://thejns.org/doi/abs/10.3171/2017.7.JNS171166

KEY WORDS deep brain stimulation; interventional MRI; stereotactic technique; Parkinson's disease; dystonia; functional neurosurgery

ABBREVIATIONS DBS = deep brain stimulation; GPi = globus pallidus pars interna; IPG = implantable pulse generator; STN = subthalamic nucleus; UPDRS = Unified Parkinson's Disease Rating Scale.

SUBMITTED May 11, 2017. ACCEPTED July 24, 2017.

INCLUDE WHEN CITING Published online January 26, 2018; DOI: 10.3171/2017.7.JNS171166. 
$\mathrm{S}$ EVERAL clinical trials have established deep brain stimulation (DBS) as a safe and effective surgical treatment for movement disorders, including Parkinson's disease and essential tremor. ${ }^{4,12,17,36}$ The ultimate success of this therapy is contingent on the accurate placement of the electrode into the target nucleus. ${ }^{1,24,37}$ This is dependent on the stereotactic technique and imaging modality used to define the boundaries of the target. Awake, intraoperative microelectrode recording coupled with macrostimulation is still used by many centers to compensate for stereotactic error and imaging limitations and thus remains the gold standard. However, awake mapping is poorly tolerated by some DBS surgery candidates. Reasons for this include anxiety, claustrophobia, a high-amplitude tremor, or dystonic posturing. For others, the specter of participating during the awake testing deters them from even contemplating surgery.

In the last few years, offering DBS with general anesthesia and real-time or near-real-time intraoperative MRI or CT scanning has emerged as an alternative for these patients. Early reports by Starr and Larson ushered in this new era that was quickly adopted by many centers, including our own, and opened the door for many patients who otherwise would have avoided a beneficial treatment. ${ }^{18,21,22}$ There are several commercially available options for intraoperative imaging at present, including diagnostic MRI suites, ${ }^{18}$ operating rooms with mobile magnets, ${ }^{30}$ and implantation using a CT-guided approach. ${ }^{8}$

Previous studies have evaluated the outcomes of patients who underwent DBS implantation under general anesthesia using frameless systems guided by intraoperative MRI and frame-based or frameless systems using intra- operative CT..$^{5,8,25}$ We present the first study to report the outcomes of patients implanted with a frame-based stereotactic system using intraoperative MRI guidance.

\section{Methods}

This study was reviewed and approved by the Cleveland Clinic institutional review board and exempted from obtaining individual informed consent due to the nature of the study, which consisted of a retrospective review of medical records and images.

\section{Patient Selection}

We selected patients who, between February 2011 and September 2014, underwent implantation of DBS leads for movement disorders after the induction of anesthesia and with the aid of intraoperative MRI. Only patients in whom a frame-based technique was used during implantation were included in this study. The patients were selected for DBS implantation under general anesthesia for the following reasons: pain and posture changes in the off-stimulation state, discomfort with supine positioning, airway concerns, claustrophobia, anxiety, history of panic during prior attempts with awake surgery, and patient preference.

\section{Surgical Technique and Imaging Protocols}

Figure 1 illustrates the intraoperative MRI and operating room setup. All procedures were performed using a $\mathrm{G}$ model Leksell frame (Elekta $\mathrm{AB}$ ). Frame fixation occurred on the day of surgery after induction of general endotracheal anesthesia (Fig. 2). This is a significant ad-

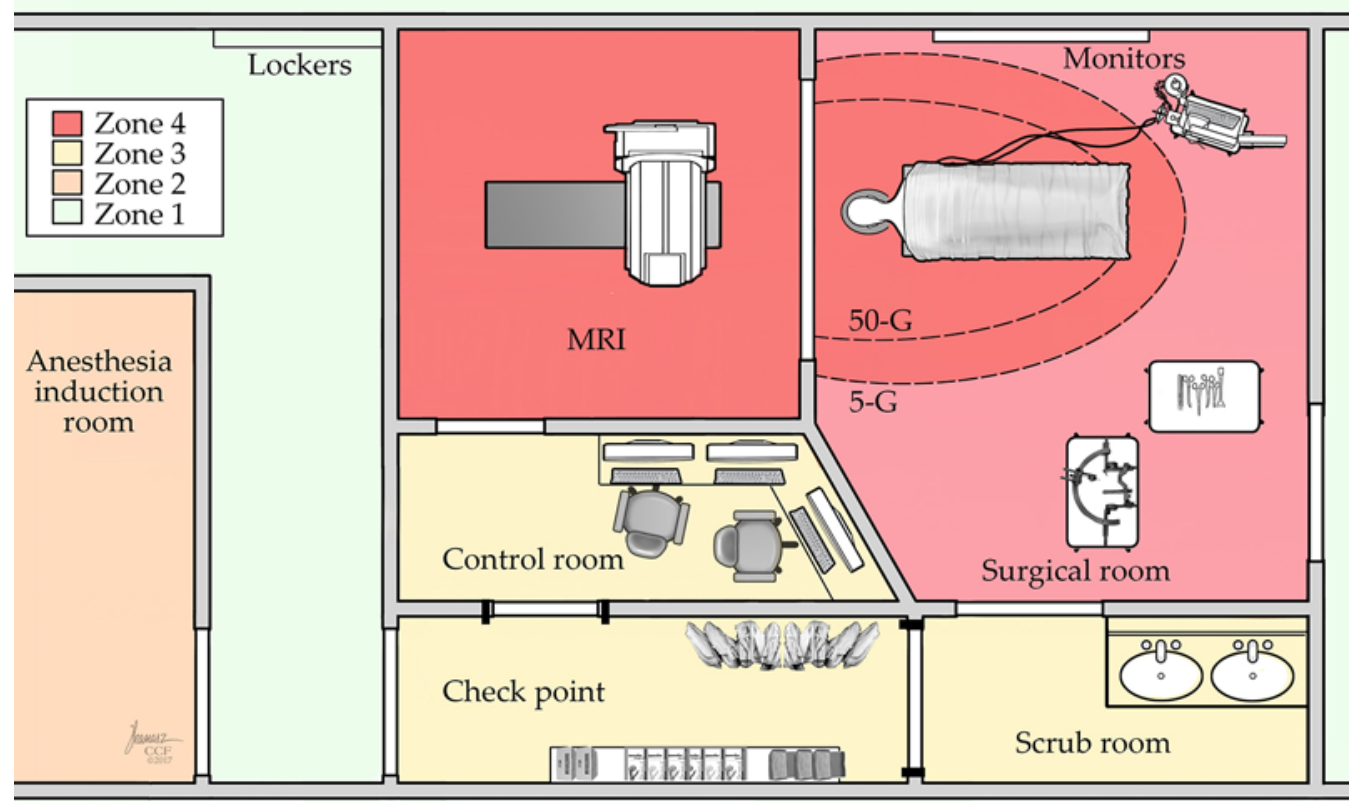

FIG. 1. Intraoperative MRI and operating room setup. Zones 1-4 are demarcated for patient and staff safety. Zone 1 (light green) is the safe zone for patients, family members, and staff. Zone 2 (orange) is the anesthesia induction room in which general endotracheal anesthesia induction takes place. Zone 3 (yellow) is restricted to intraoperative MRI and operating room personnel. Zone 4 (red and pink) is the danger zone. Non-MRI-compatible instruments and devices are placed in the pink area (outside the 5-G line). Inside the $50-\mathrm{G}$ line, the magnet comes into the operative room to scan the patient. Reprinted with permission, Cleveland Clinic Center for Medical Art \& Photography @ 2017. All rights reserved. Figure is available in color online only. 


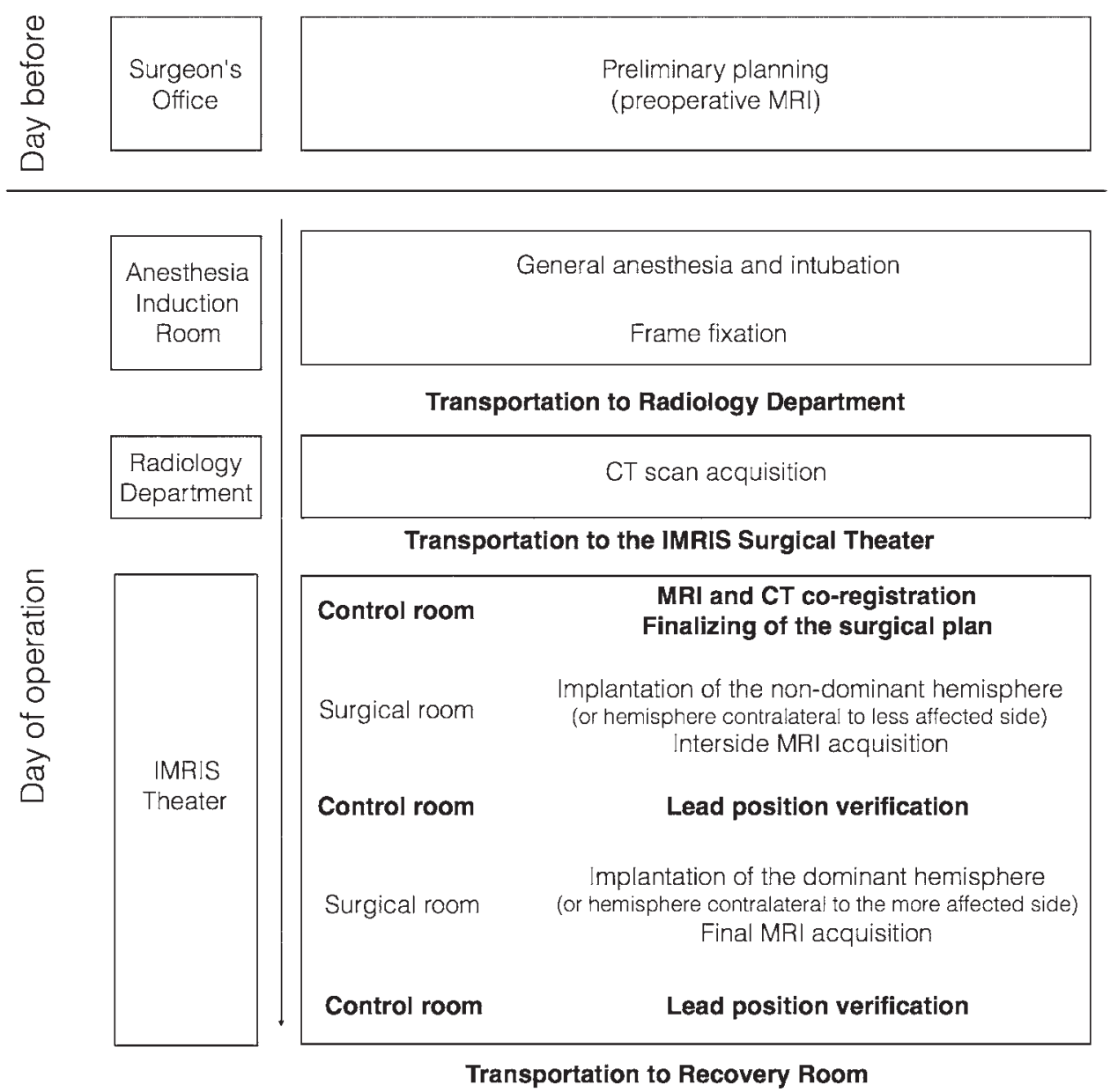

FIG. 2. Workflow of surgical technique and imaging protocols.

vantage of this workflow as it obviates any need for fiducial placement prior to the patient undergoing anesthesia. Volumetric stereo-CT scans were acquired and fused to the preoperative MR images using stereotactic surgical planning software (iPlan 3.0, BrainLab AG). All MR images (volumetric Gd-enhanced T1-weighted images, coronal T2-weighted images, and axial proton density images) were acquired either prior to the day of surgery to minimize the time under general anesthesia or on the day of surgery. In some cases, when preoperative MR images were deemed inadequate for targeting due to movement artifact, new images were obtained in the operating room utilizing the intraoperative magnet. The MR images and CT scans were fused, and frame-based coordinates were obtained based on stereo-CT findings. Target and trajectory were determined using direct and indirect targeting methods, as previously described. ${ }^{20}$

Two patients underwent unilateral implantation, and 31 underwent bilateral implantation, totaling 64 leads. A bur hole was made on the first side, and the lead was implanted with the standard frame-based techniques. No microelectrode recording was used for these patients. Immediately after implantation, T1-weighted MRI was performed, and the images were fused to the preoperative plan. Based on the location of the lead, a decision was made to reposition it if needed. Any stereotactic error identified during the first MRI session was used to correct the plan for implantation on the second side. For example, if a 1-mm error to the right was found on the first side, we would correct the plan for the second lead by $1 \mathrm{~mm}$ (or less) to the left. This technique augmented the accuracy for the index cannula penetration on the second side. To maximize the potential advantages of this workflow, we implanted the first lead in the nondominant hemisphere and the second lead in the dominant hemisphere. Once the second lead was placed, another MR image was obtained and, again, fused to the preoperative plan. The duration of surgery (defined as first skin incision to last suture), duration of anesthesia (induction to recovery), and systolic and diastolic blood pressure measures were obtained from the anesthesia records.

\section{Assessing Lead Positioning}

At our center, a postoperative CT scan obtained approximately 1 month after implantation is ordered to assess lead location after resolution of any pneumocephalus. This image is then fused to the preoperative plan, which includes the preoperative stereo-CT scan. Therefore, the method allows for assessment of lead accuracy based on frame coordinates rather than dependence on anterior commissure-posterior commissure coordinates. Target, 
frame-based coordinates $(\mathrm{x}, \mathrm{y}$, and $\mathrm{z})$ were collected from the surgical description in the patients' operative reports. Using the iPlan platform, the centroid of the artifact corresponding to the tip of the lead was targeted, yielding the lead coordinates. The vector difference between the preoperative target and the postoperative lead location coordinates and the euclidian distance between the planned target and the tip of the lead were calculated. In addition, we also evaluated lead location on the final MR image obtained during surgery to assess the difference between these findings and the 1-month postoperative CT scan, which was considered the gold standard.

\section{Outcome Variables}

Due to the limited number and great heterogeneity of symptoms in patients with dystonia $(n=6)$, only Parkinson's patients were included in the outcome analysis. To evaluate clinical outcome, different scales were used to assess quality of life (EQ-5D), activities of daily living (Unified Parkinson's Disease Rating Scale [UPDRS] part II), and motor function (UPDRS part III during off- and onmedication and off- and on-stimulation states). The scores were obtained from medical records at baseline and the last follow-up.

\section{Statistical Analysis}

The Shapiro-Wilk test was used to evaluate normality of the data. The paired t-test and Wilcoxon rank-sum test were used to measure baseline and follow-up outcomes. A 1-sided t-test with a cutoff of less than $1 \mathrm{~mm}$ was used to evaluate the accuracy of lead implantation. A 2-sided t-test was used to compare the accuracy between the first and second sides of implantation. Finally, the Wilcoxon signed-rank test was used to compare the difference between intraoperative MRI accuracy and postoperative CT scan accuracy. Any variable with $\mathrm{p}<0.05$ was considered to be statistically significant.

\section{Results \\ Overall Results}

A total of 64 leads were implanted in 33 patients (17 female and 16 male). Two patients had unilateral DBS. Six patients had a diagnosis of dystonia, and 27 patients had Parkinson's disease. The globus pallidus pars interna (GPi) was the target for 31 patients, and the subthalamic nucleus (STN) was the target for 2 patients. Age, duration of surgery, duration of anesthesia, and intraoperative blood pressure values are summarized in Table 1.

\section{Clinical Outcomes}

The mean follow-up period was 9.1 months (SD 5.8 months); $74 \%$ of the patients completed clinical outcomes evaluation during follow-up. The clinical outcomes evaluation of the remaining $26 \%$ of patients was not included because the patients chose to undergo follow-up locally or the data were incomplete or not retrievable from the medical records. The EQ-5D score improved or remained stable for $71 \%$ of the patients, with a mean improvement of 0.063 points (SD 0.087 points), whereas $29 \%$ of the pa-
TABLE 1. Overall results in 33 patients under general anesthesia who underwent DBS lead implantation

\begin{tabular}{lrr}
\hline \multicolumn{1}{c}{ Variable } & Mean & \multicolumn{1}{c}{ SD } \\
\hline Age (yrs) & 67.2 & 6.4 \\
\hline Duration of disease (yrs) & 12.7 & 6.9 \\
\hline Last follow-up (mos) & 9.1 & 5.8 \\
\hline Duration of anesthesia (mins) & 431.0 & 85.8 \\
\hline Duration of surgery (mins) & 265.3 & 74.7 \\
\hline Maximum systolic blood pressure $(\mathrm{mm} \mathrm{Hg})$ & 160.2 & 21.0 \\
\hline Minimum systolic blood pressure $(\mathrm{mm} \mathrm{Hg})$ & 91.6 & 11.5 \\
\hline Maximum diastolic blood pressure $(\mathrm{mm} \mathrm{Hg})$ & 88.0 & 13.5 \\
\hline Minimum diastolic blood pressure $(\mathrm{mm} \mathrm{Hg})$ & 47.8 & 9.0 \\
\hline
\end{tabular}

tients reported a worse quality of life score, with a mean decrease of 0.191 points (SD 0.173 points).

Table 2 summarizes UPDRS scores (parts II and III) in different scenarios. When in the off-medication/on-stimulation state, all patients reported significant improvement in the UPDRS III scores at the last follow-up ( $<<0.001)$ compared with the preoperative off-medication condition, with a reduction of 25.2 points $(46.3 \%$ ) (SD 14.7 points and $23.5 \%$, respectively). For the on-medication/on-stimulation state, there was a nonsignificant reduction of 0.2 points $(p=0.93)$. There was improvement or stability of the UPDRS II for $68 \%$ of the Parkinson's patients, with a mean decrease of 6.6 points (SD 5.4), and worsening occurred for $32 \%$ of these patients, with a mean increase of 8.8 points (SD 5.2). There was no significant difference $(\mathrm{p}=0.35)$ between baseline and last follow-up UPDRS II scores (Table 2).

\section{Placement Accuracy}

For 2 patients, the stereotactic error was deemed to be significant based on intraoperative MRI findings (i.e., the MR image acquired after the first lead was implanted). In these patients, the lead was removed and replaced after correcting for the error. There was an error of $3.0 \mathrm{~mm}$ lateral to the intended target in one case, and an error of 2.5 $\mathrm{mm}$ medial and $1.0 \mathrm{~mm}$ posterior to the planned target in the other case. Lead revision was not deemed necessary in any of the patients after the last intraoperative MRI session.

Based on the last intraoperative MR image, the mean difference between the tip of the electrode and the planned target was $0.82 \mathrm{~mm}$ (SD 0.5, $\mathrm{p}=0.006$ ) for the $\mathrm{x}$-axis, 0.67 $\mathrm{mm}$ (SD 0.5, p < 0.001) for the y-axis, and $0.78 \mathrm{~mm}$ (SD $0.7, \mathrm{p}=0.008$ ) for the $\mathrm{z}$-axis. On average the euclidian distance was $1.52 \mathrm{~mm}(\mathrm{SD} 0.6, \mathrm{p}=1.0$ ) (Table 3).

Accuracy was further evaluated comparing the first implanted side and the second implanted side. There was a significant mediolateral (x-axis) difference $(\mathrm{p}=0.02)$ in accuracy between the first (mean $1.02 \mathrm{~mm}, \mathrm{SD} 0.57 \mathrm{~mm}$ ) and the second (mean $0.66 \mathrm{~mm}, \mathrm{SD} 0.50 \mathrm{~mm}$ ) sides. However, no significant difference was found for the $y$ - and $\mathrm{z}$-axes ( $\mathrm{p}=0.10$ and $\mathrm{p}=0.89$, respectively). For the $\mathrm{y}$-axis, the accuracy mean was $0.58 \mathrm{~mm}(\mathrm{SD} 0.44 \mathrm{~mm})$ on the first side and $0.78 \mathrm{~mm}$ (SD $0.48 \mathrm{~mm}$ ) on the second side. 
TABLE 2. Clinical outcomes

\begin{tabular}{|c|c|c|c|c|c|c|c|c|c|}
\hline \multirow[b]{3}{*}{ Variable } & & & & & \multirow{3}{*}{$\begin{array}{c}p \\
\text { Value }\end{array}$} & \multicolumn{4}{|c|}{ Score Difference Btwn Baseline \& Last Follow-Up } \\
\hline & \multicolumn{2}{|c|}{ Baseline } & \multicolumn{2}{|c|}{ Last Follow-Up } & & \multicolumn{2}{|c|}{ Absolute Value } & \multicolumn{2}{|c|}{$\%$} \\
\hline & Mean & SD & Mean & SD & & Mean & SD & Mean & SD \\
\hline UPDRS II & 19.3 & 6.2 & 17.4 & 10.0 & 0.35 & -1.8 & 8.7 & -4.25 & 47.9 \\
\hline UPDRS III off* & 52.8 & 14.9 & 28.6 & 11.9 & $<0.001$ & -25.2 & 14.7 & -46.3 & 23.5 \\
\hline UPDRS III on† & 22.7 & 8.2 & 22.5 & 9.2 & 0.93 & -0.2 & 10.2 & 5.6 & 52.0 \\
\hline
\end{tabular}

For the z-axis, the mean accuracy was $0.79 \mathrm{~mm}$ (SD 0.90 $\mathrm{mm}$ ) for the first side and $0.82 \mathrm{~mm}$ (SD $0.54 \mathrm{~mm}$ ) for the second side.

\section{Complications}

There were surgical complications in 5 patients. The only intraoperative complication was a small, asymptomatic hemorrhage without significant mass effect that was detected in 1 patient and required no surgical intervention. One patient complained of persistent pain at the implantable pulse generator (IPG) site. This resolved after the device was reimplanted on the opposite side. Three patients presented with wound infection postoperatively. Two of these patients had infection at the IPG site, one at 3 months and the other at 1 month after surgery. These patients were treated with IPG removal, oral antibiotics, and further IPG reimplantation. The remaining patient presented with a traumatic laceration of the scalp near 1 lead 1 month after the surgery. The patient underwent removal of the IPG and was treated with antibiotics.

\section{Discussion}

Intraoperative MRI was developed in the 1990s to enable real-time imaging of the intracranial anatomy during brain tumor surgery with the expectation that this would improve the safety and the volume of tumor that could be resected..$^{10,32}$ By co-opting this modality for their own purposes, functional neurosurgeons have been able to apply it to their patients with movement disorders who are eligible for DBS. As accurate lead placement is of paramount importance in this type of surgery, intraoperative MRI will have significant benefits for some patients. High-resolution images acquired with intraoperative MRI visualize the position of the DBS leads relative to the target nucleus, which is far superior to what is generally achievable with CT. Intraoperative MRI thus seems to overcome some of the limitations associated with implantation of the leads under general anesthesia with CT or fluoroscopy and also limits the radiation exposure.

Frame-based implantations performed under general anesthesia or conscious sedation with an immediate postoperative MRI for accuracy verification have been reported. ${ }^{11,19}$ To the best of our knowledge, our study is the first report in the literature with clinical outcomes using a commercial DBS frame system coupled with intraoperative MRI in patients under general anesthesia.

Several studies support DBS implantation under gener- al anesthesia with intraoperative imaging as an alternative to awake surgery. $8,14,25,27,31$ Several implantation techniques have been reported. In 2002, a frameless skull-mounted device was developed to implant DBS leads under general anesthesia in a standard MRI diagnostic space. ${ }^{21}$ Since then, several centers have adopted this technique. ${ }^{7,22,31,33}$ Detection of pneumocephalus and brain shift may be used to correct or refine subsequent targeting adjustments. However, whether image-guided lead implantation will replace intraoperative neurophysiological assessment remains a matter of debate. ${ }^{14,27,31,38}$ Refinements in electrodes together with intraoperative imaging may relegate awake mapping to only a small subset of cases in the future.

A recent meta-analysis comparing outcomes after awake and asleep DBS showed no difference in motor outcomes between the 2 techniques. However, the analysis suggested that there might be a lower overall intraoperative complication rate with asleep DBS but a higher rate of stimulation-related complications compared with awake DBS. ${ }^{16}$ In their study, Chen et al. ${ }^{9}$ found no difference in complication rates between awake and asleep DBS at a single center, but that study did not evaluate the motor outcomes between the 2 cohorts.

Our patients experienced an improvement of $46.3 \%$ in motor function outcomes (UPDRS III off-medication state). This efficacy is comparable to the rates in studies that included patients who underwent implantation with awake intraoperative physiology, ${ }^{26,36}$ as well as patients whose implantation procedures were guided by intraoperative MRI. ${ }^{6,28,29}$ Ostrem et al. reported a $40.2 \%$ improvement in UPDRS III scores with the ClearPoint system in a prospective study of 26 patients with bilateral STN or

TABLE 3. Accuracy of lead placement

\begin{tabular}{|c|c|c|c|c|c|c|}
\hline \multirow[b]{2}{*}{ Variable } & \multicolumn{3}{|c|}{$\begin{array}{c}\text { Planned Target vs } \\
\text { Intraop MRI }\end{array}$} & \multicolumn{3}{|c|}{$\begin{array}{c}\text { Intraop MRI vs } \\
\text { Postop CT }\end{array}$} \\
\hline & Mean & SD & p Value* & Mean & SD & $p$ Value* \\
\hline$x(\mathrm{~mm})$ & 0.82 & 0.5 & 0.006 & 0.51 & 0.4 & $<0.001$ \\
\hline y $(\mathrm{mm})$ & 0.67 & 0.5 & $<0.001$ & 1.05 & 0.9 & 0.69 \\
\hline $\mathrm{z}(\mathrm{mm})$ & 0.78 & 0.7 & 0.008 & 0.89 & 0.7 & 0.11 \\
\hline $\begin{array}{l}\text { Euclidian distance } \\
\qquad(\mathrm{mm})\end{array}$ & 1.52 & 0.6 & & 1.66 & 0.9 & \\
\hline
\end{tabular}

$x, y$, and $z$ represent the distances between the tip of the electrode and the planned target on each cartesian axis.

* One-sided t-test with < 1-mm significance. 
GPi lead implantations. ${ }^{29}$ Hamani et al., in a meta-analysis of cohort studies for STN DBS, reported an average improvement of $52 \%$ over baseline in the UPDRS III offmedication score. ${ }^{15}$ Of note, the majority of our patients underwent lead implantation in the GPi, potentially limiting some of the motor benefits compared with those of the STN. Aviles-Olmos et al. reported good long-term outcomes $(77.2 \%$ tremor reduction, $50 \%$ rigidity reduction, and $23.2 \%$ bradykinesia reduction) 8 years after surgery. ${ }^{2,14}$ Although the procedures were not performed in an intraoperative MRI suite as in our series, their experience strengthens the idea that image-guided approaches have results comparable to those of implantation guided by awake physiology.

In addition to motor improvements, we also noted adequate accuracy and precision for lead placement. Only 2 leads were repositioned intraoperatively after the first scan (3\%), and none of the leads were revised postoperatively. Our results demonstrate a mean error of 1.52 $\mathrm{mm}$ in the 3D space, slightly smaller than the inaccuracy $(1.8 \mathrm{~mm})$ reported by Thani et al. using a framed MRIdirected implantable guide-tube technique, placing carbothane stylettes before implantation of leads. ${ }^{35}$ Southwell et al. reported radial errors of $0.68 \mathrm{~mm}$ and $0.78 \mathrm{~mm}$ when comparing 1.5-T and 3-T intraoperative MRI, respectively, with the ClearPoint system. ${ }^{34}$ Interestingly, we noted a significant difference in error between the first lead implanted and the second, with better accuracy on the second side. This may be related to the stereotactic correction we apply after evaluating the extent and direction of error on the intraoperative scan after the first lead is implanted in one hemisphere.

Our rate of complications dropped to $4 \%$ in the last 2 years of our series. Still, the infection rate for patients who underwent implantation under general anesthesia is higher than that in patients undergoing awake DBS implantation with intraoperative physiology, for which we have had an infection rate below $2 \%$ in the past 7 years. The reasons for this difference are unclear but may be related to duration of surgery, differences in the operating room, workflow, or patient selection bias. Bhatia et al., in a review of 35 studies comprising 3550 patients, found a postoperative rate of infection in DBS surgery ranging from $0 \%$ to $15 \%$, with a mean for all data of $4.7 \% .^{3}$ Likewise, Martin et al. reported a $2.6 \%$ infection rate in 10 years with the use of the ClearPoint system when excluding the first 11 patients in their series. ${ }^{23}$

This study has limitations. First, this is a retrospective cohort of patients, and outcome scores were obtained from medical records instead of a blinded evaluation of the UPDRS videos. Second, there might exist selection bias. We perform more implantations in the STN than in the GPi in our practice, although this sample had a greater proportion of patients with GPi implantation. This may reflect a concern by our movement disorder team for a greater risk of cognitive change in the patients selected for asleep DBS. Third, our group has previously shown that preoperative cognitive status is a predictor of quality of life postoperatively..$^{13}$ This may explain why approximately $25 \%$ of patients reported a decline in quality of life after DBS in this sample.

\section{Conclusions}

Frame-based DBS implantation under general anesthesia with intraoperative MRI verification of lead location is safe, accurate, precise, and effective compared with standard implantation performed with awake intraoperative physiology. More clinical trials are necessary to directly compare outcomes associated with each technique.

\section{References}

1. Andrade-Souza YM, Schwalb JM, Hamani C, Eltahawy H, Hoque T, Saint-Cyr J, et al: Comparison of three methods of targeting the subthalamic nucleus for chronic stimulation in Parkinson's disease. Neurosurgery 56 (2 Suppl):360-368, 2005

2. Aviles-Olmos I, Kefalopoulou Z, Tripoliti E, Candelario J, Akram H, Martinez-Torres I, et al: Long-term outcome of subthalamic nucleus deep brain stimulation for Parkinson's disease using an MRI-guided and MRI-verified approach. J Neurol Neurosurg Psychiatry 85:1419-1425, 2014

3. Bhatia R, Dalton A, Richards M, Hopkins C, Aziz T, Nandi $\mathrm{D}$ : The incidence of deep brain stimulator hardware infection: the effect of change in antibiotic prophylaxis regimen and review of the literature. Br J Neurosurg 25:625-631, 2011

4. Blomstedt P, Hariz GM, Hariz MI, Koskinen LOD: Thalamic deep brain stimulation in the treatment of essential tremor: a long-term follow-up. Br J Neurosurg 21:504-509, 2007

5. Burchiel KJK, McCartney S, Lee A, Raslan AMA: Accuracy of deep brain stimulation electrode placement using intraoperative computed tomography without microelectrode recording. J Neurosurg 119:301-306, 2013

6. Chabardes S, Isnard S, Castrioto A, Oddoux M, Fraix V, Carlucci L, et al: Surgical implantation of STN-DBS leads using intraoperative MRI guidance: technique, accuracy, and clinical benefit at 1-year follow-up. Acta Neurochir (Wien) 157:729-737, 2015

7. Chansakul T, Chen PN Jr, Lee TC, Tierney T, Interventional MR: Interventional MR imaging for deep-brain stimulation electrode placement. Radiology 281:940-946, 2016

8. Chen T, Mirzadeh Z, Chapple K, Lambert M, Dhall R, Ponce FA: "Asleep" deep brain stimulation for essential tremor. J Neurosurg 124:1842-1849, 2016

9. Chen T, Mirzadeh Z, Chapple K, Lambert M, Ponce FA: Complication rates, lengths of stay, and readmission rates in "awake" and "asleep" deep brain simulation. J Neurosurg 127:360-369, 2017

10. Coburger J, Merkel A, Scherer M, Schwartz F, Gessler F, Roder C, et al: Low-grade glioma surgery in intraoperative magnetic resonance imaging: Results of a multicenter retrospective assessment of the German Study Group for Intraoperative Magnetic Resonance Imaging. Neurosurgery 78:775-786, 2016

11. Cui Z, Pan L, Song H, Xu X, Xu B, Yu X, et al: Intraoperative MRI for optimizing electrode placement for deep brain stimulation of the subthalamic nucleus in Parkinson disease. J Neurosurg 124:62-69, 2016

12. Deuschl G, Schade-Brittinger C, Krack P, Volkmann J, Schäfer H, Bötzel K, et al: A randomized trial of deep-brain stimulation for Parkinson's disease. N Engl J Med 355:896908, 2006

13. Floden D, Cooper SE, Griffith SD, Machado AG: Predicting quality of life outcomes after subthalamic nucleus deep brain stimulation. Neurology 83:1627-1633, 2014

14. Foltynie T, Zrinzo L, Martinez-Torres I, Tripoliti E, Petersen E, Holl E, et al: MRI-guided STN DBS in Parkinson's disease without microelectrode recording: efficacy and safety. J Neurol Neurosurg Psychiatry 82:358-363, 2011 
15. Hamani C, Richter E, Schwalb JM, Lozano AM: Bilateral subthalamic nucleus stimulation for Parkinson's disease: a systematic review of the clinical literature. Neurosurgery 56:1313-1324, 2005

16. Ho AL, Ali R, Connolly ID, Henderson JM, Dhall R, Stein SC, et al: Awake versus asleep deep brain stimulation for Parkinson's disease: a critical comparison and meta-analysis. J Neurol Neurosurg Psychiatry [epub ahead of print], 2017

17. Krack P, Batir A, Van Blercom N, Chabardes S, Fraix V, Ardouin $\mathrm{C}$, et al: Five-year follow-up of bilateral stimulation of the subthalamic nucleus in advanced Parkinson's disease. $\mathbf{N}$ Engl J Med 349:1925-1934, 2003

18. Larson PS, Starr PA, Bates G, Tansey L, Richardson RM, Martin AJ: An optimized system for interventional MRI guided stereotactic surgery: preliminary evaluation of targeting accuracy. Neurosurgery 70 (1 Suppl Operative):95-103, 2011

19. Lee MWY, De Salles AAF, Frighetto L, Torres R, Behnke E, Bronstein JM: Deep brain stimulation in intraoperative MRI environment - comparison of imaging techniques and electrode fixation methods. Minim Invasive Neurosurg 48:1-6, 2005

20. Machado A, Rezai AR, Kopell BH, Gross RE, Sharan AD, Benabid AL: Deep brain stimulation for Parkinson's disease: surgical technique and perioperative management. Mov Disord 21 (Suppl 14):S247-S258, 2006

21. Martin AJ, Larson PS, Ostrem JL, Sootsman WK, Talke P, Weber OM, et al: Placement of deep brain stimulator electrodes using real-time high-field interventional magnetic resonance imaging. Magn Reson Med 54:1107-1114, 2005

22. Martin AJ, Larson PS, Ostrem JL, Starr PA: Interventional magnetic resonance guidance of deep brain stimulator implantation for Parkinson disease. Top Magn Reson Imaging 19:213-221, 2009

23. Martin AJ, Larson PS, Ziman N, Levesque N, Volz M, Ostrem JL, et al: Deep brain stimulator implantation in a diagnostic MRI suite: infection history over a 10 -year period. J Neurosurg 126:108-113, 2017

24. Matias CM, Mehanna R, Cooper SE, Amit A, Lempka SF, Silva D, et al: Correlation among anatomic landmarks, location of subthalamic deep brain stimulation electrodes, stimulation parameters, and side effects during programming monopolar review. Neurosurgery 11 (Suppl 2):99-109, 2015

25. Mirzadeh Z, Chapple K, Lambert M, Evidente VG, Mahant P, Ospina MC, et al: Parkinson's disease outcomes after intraoperative CT-guided "asleep" deep brain stimulation in the globus pallidus internus. J Neurosurg 124:902-907, 2016

26. Moro E, Lozano AM, Pollak P, Agid Y, Rehncrona S, Volkmann J, et al: Long-term results of a multicenter study on subthalamic and pallidal stimulation in Parkinson's disease. Mov Disord 25:578-586, 2010

27. Nakajima T, Zrinzo L, Foltynie T, Olmos IA, Taylor C, Hariz MI, et al: MRI-guided subthalamic nucleus deep brain stimulation without microelectrode recording: can we dispense with surgery under local anaesthesia? Stereotact Funct Neurosurg 89:318-325, 2011

28. Ostrem JL, Galifianakis NB, Markun LC, Grace JK, Martin AJ, Starr PA, et al: Clinical outcomes of PD patients having bilateral STN DBS using high-field interventional MR-imaging for lead placement. Clin Neurol Neurosurg 115:708-712, 2013
29. Ostrem JL, Ziman N, Galifianakis NB, Starr PA, San Luciano M, Katz M, et al: Clinical outcomes using ClearPoint interventional MRI for deep brain stimulation lead placement in Parkinson's disease. J Neurosurg 124:908-916, 2016

30. Rahmathulla G, Recinos PF, Traul DE, Avitsian R, Yunak M, Harper NT, et al: Surgical briefings, checklists, and the creation of an environment of safety in the neurosurgical intraoperative magnetic resonance imaging suite. Neurosurg Focus 33(5):E12, 2012

31. Saleh S, Swanson KI, Lake WB, Sillay KA: Awake neurophysiologically guided versus asleep MRI-guided STN DBS for Parkinson disease: a comparison of outcomes using levodopa equivalents. Stereotact Funct Neurosurg 93:419426,2015

32. Senft C, Bink A, Franz K, Vatter H, Gasser T, Seifert V: Intraoperative MRI guidance and extent of resection in glioma surgery: a randomised, controlled trial. Lancet Oncol 12:997-1003, 2011

33. Sidiropoulos C, Rammo R, Merker B, Mahajan A, LeWitt P, Kaminski P, et al: Intraoperative MRI for deep brain stimulation lead placement in Parkinson's disease: 1 year motor and neuropsychological outcomes. J Neurol 263:1226-1231, 2016

34. Southwell DG, Narvid JA, Martin AJ, Qasim SE, Starr PA, Larson PS: Comparison of deep brain stimulation lead targeting accuracy and procedure duration between 1.5- and 3-tesla interventional magnetic resonance imaging systems: an initial 12-month experience. Stereotact Funct Neurosurg 94:102-107, 2016

35. Thani NB, Bala A, Lind CRP: Accuracy of magnetic resonance imaging-directed frame-based stereotaxis. Neurosurgery 70 (1 Suppl Operative):114-124, 2012

36. Weaver FM, Follett K, Stern M, Hur K, Harris C, Marks WJ $\mathrm{Jr}$, et al: Bilateral deep brain stimulation vs best medical therapy for patients with advanced Parkinson disease: a randomized controlled trial. JAMA 301:63-73, 2009

37. Wodarg F, Herzog J, Reese R, Falk D, Pinsker MO, Steigerwald F, et al: Stimulation site within the MRI-defined STN predicts postoperative motor outcome. Mov Disord 27:874879, 2012

38. Zrinzo L, Hariz M, Hyam JA, Foltynie T, Limousin P: A paradigm shift toward MRI-guided and MRI-verified DBS surgery. J Neurosurg 124:1135-1138, 2016 (Letter)

\section{Disclosures}

Dr. Machado: consultant for St. Jude Abbott, Spinal Modulation, Functional Neuromodulation and Deep Brain Innovation, and Enspire; patent holder with Enspire, ATI, and Cardionomics; and fellowship support from Medtronic.

\section{Author Contributions}

Conception and design: Machado, Matias. Acquisition of data: Matias, Frizon. Analysis and interpretation of data: Machado, Matias, Frizon. Drafting the article: Matias, Frizon. Critically revising the article: Machado, Nagel, Lobel.

\section{Correspondence}

André Machado: Cleveland Clinic Neurological Institute, Cleveland, OH. machada@ccf.org. 